\title{
Functional variations of NFKB1 and NFKB1A in inflammatory disorders and their implication for therapeutic approaches
}

\author{
Gonul Kanigur-Sultuybek ${ }^{1, *}$, Guven Yenmis ${ }^{2}$, Tugba Soydas ${ }^{1}$
}

\section{Abstract}

\begin{abstract}
Nuclear factor $\kappa$-light-chain-enhancer of activated B cells $(\mathrm{NF}-\kappa \mathrm{B})$ is a sophisticated transcription factor that is particularly important in the inflammatory response, but it regulates more than 400 individual and dependent genes for parts of the apoptotic, angiogenic, and proliferative, differentiative, and cell adhesion pathways. NF- $\kappa \mathrm{B}$ function is directly inhibited by the binding of inhibitor of $\kappa \mathrm{B}(\mathrm{I} \kappa \mathrm{B})$, and the imbalance between $\mathrm{NF}-\kappa \mathrm{B}$ and I $\kappa \mathrm{B}$ has been linked to the development and progression of cancer and a variety of inflammatory disorders. These observations might broaden the horizon of current knowledge, particularly on the pathogenesis of inflammatory diseases considering the roles of NF- $\mathrm{KB}$ and $\mathrm{I} \kappa \mathrm{B}$. In this context, we focus this narrative review on a comparative discussion of our findings with other literature regarding variations of NFKB1 and NFKB1A and their association with susceptibility to widespread inflammatory disorders (such as atherosclerosis, morbid obesity, Behçet syndrome, Graves disease, Hashimoto disease) and common cancers (such as gliomas).
\end{abstract}

Keywords: I-kappa B proteins; inflammation mediators; neoplasms; NF-kappa B; polymorphism; single nucleotide

Inflammation, a requisite process in the pathogenesis of several disorders, is coupled with the enhanced gene expression of the immune regulators [1]. Nuclear factor $\kappa$-light-chain-enhancer of activated $\mathrm{B}$ cells $(\mathrm{NF}-\kappa \mathrm{B})$, a prominent pleiotropic transcription factor, organizes a broad range of genes required for the distinct processes of the inflammatory and immune responses by displaying critical roles in the development of autoimmunity [2]. The NF- $\kappa \mathrm{B}$ family in mammals consists of five Rel homology domain-containing proteins in mammals, namely, p50/p105, p65/RelA, p52/p100, RelB, and c-Rel, present in a homo- or heterodimerized formation. The most commonly observed heterodimer forms of NF- $\kappa B$ are the $\mathrm{p} 50$ and the p65 (also known as RelA), encoded by NFKB1 and NFKB2, respectively. NFKB1-having 24 exons, spanning $156 \mathrm{~kb}$, and being strongly associated with inflammation and immunity - encodes the genes for the p50 and p105 NF- $\kappa$ B isoforms, which are always-ready transcription regulators remarkable for their association with the pathological states of many diseases $[2,3]$. NFKBIA (NF- $\mathrm{KB}$ inhibitor, $\alpha$ ), having 6 exons and located on chromosome $14 \mathrm{q} 13$, instead, encodes

*Correspondence to: Gonul Kanigur-Sultuybek, Department of Medical Biology and Genetics, Faculty of Medicine, Istanbul Aydin University, Sefakoy-Kucukcekmece, Istanbul 34295, Turkey, e-mail: kanigur@istanbul.edu.tr

1 Department of Medical Biology and Genetics, Faculty of Medicine, Istanbul Aydin University, Istanbul 34295, Turkey

${ }^{2}$ Department of Medical Biology and Genetics, Faculty of Medicine, Biruni University, Istanbul 34010, Turkey

¿ Open Access. ๑ 2020 Kanigur-Sultuybek et al., published by Sciendo. (cc)BY-NC-ND This work is licensed under the Creative Commons Attribution NonCommercial-NoDerivatives 4.0 License. 
the alpha subunit of the inhibitor of $\kappa \mathrm{B}(\mathrm{I} \kappa \mathrm{B} \alpha)$, a typical form of the I $\kappa \mathrm{B}$ family that naturally sequesters the $\mathrm{NF}-\kappa \mathrm{B}$ proteins within the cytoplasm [4].

The variations present in the genes responsible for the syn-

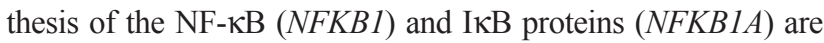
thus considered to exist in inflammatory disorders and cancer pathogenesis. So far, the U.S. National Center for Biotechnology Information (NCBI) database has 25,820 single-nucleotide polymorphisms (SNPs) reports on NFKB1 (accessed March $25,2020)$. The most studied variation rs28362491 ( -94 ins/ del ATTG) is present within the promoter region of NFKB1 (Figure 1). Owing to its presence between two essential promoter regulatory elements, only this variation (of the 6 variations is known to have a likely functional behavior modulating nuclear protein binding to the $N F K B 1$ promoter site [5].

$\mathrm{I} \kappa \mathrm{B} \alpha$, conversely, includes a number of polymorphisms. NFKBIA $-881 \mathrm{~A} / \mathrm{G},-519 \mathrm{C} / \mathrm{T}$, and $-826 \mathrm{C} / \mathrm{T}$ variations, respectively located at putative binding sites for transcription factors retinoic acid-related orphan receptor $\alpha$, CCAAT/ enhancer-binding protein, and GATA binding protein 2, may regulate expression of the genes for $\mathrm{I} \kappa \mathrm{B} \alpha$ and indirectly $\mathrm{NF}-\kappa \mathrm{B}$ activation $[5,6]$. Another well-studied variant, namely, rs696 (3' untranslated region [UTR] $A \rightarrow G$ polymorphism; Figure 1), alters NF- $\kappa \mathrm{B}$ activity [7]. There is a general agreement on the involvement of an imbalance of I $\mathrm{B}$ and NF- $\kappa \mathrm{B}$ in a wide variety of diseases, yet, the mechanisms behind how functional changes within numerous genes are associated with disease development remain to be elucidated. We consider that evaluation of studies of $N F K B 1$ and $N F K B 1 A$ polymorphisms may open a beneficial window to establish the connection between these two genes, if any, in inflammationrelated diseases.

The present narrative review is based mainly on a comparative discussion of our findings with other literature regarding variations of $N F K B 1$ and $N F K B 1 A$ and their association with susceptibility to widespread inflammatory disorders (such as atherosclerosis [AT, morbid obesity, Behçet syndrome, Graves disease, Hashimoto disease) and common cancers (such as gliomas).

\section{NFKB1 and NFKB1A variants and their relation to inflammatory disorders}

As a widespread transcription factor in every mammalian cell dominating the gene expression of many acute-phase proteins such as cell adhesion molecules, chemokines, growth factors, and cytokines $[8,9], \mathrm{NF}-\kappa \mathrm{B}$ manages the gene products required for both adaptive and innate immune responses. NF- $\kappa \mathrm{B}$ is activated after intra- or extracellular stimuli, such as viral products, cytokines, and ultraviolet irradiation $[10,11]$. In an unstimulated phase, NF- $\kappa \mathrm{B}$ proteins are present within the cytoplasm in their sequestered homo- or heterodimer formation and interact with IкB inhibitors [12].

\section{NFKB1A}

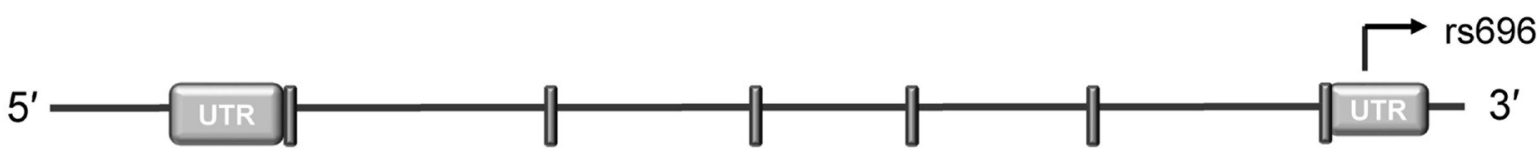

Promoter region

NFKB1

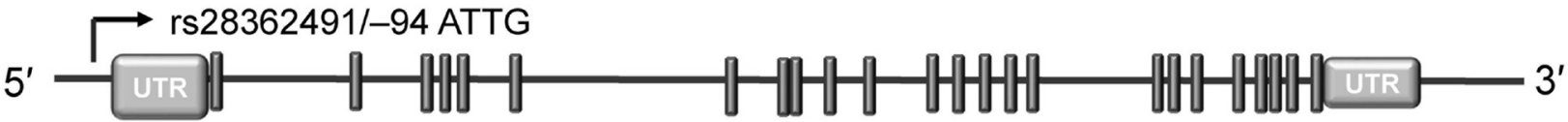

Promoter region

Exon

Figure 1. NFKB1A 3'-UTR (rs696) and NFKB1-94ATTG (rs28362491) polymorphisms. UTR, untranslated region. 
NF- $\mathrm{\kappa B}$ signaling is critically involved in both cancer development and inflammation pathways first by enhancing antiapoptosis, proliferation, and angiogenesis and, second, by repressing immune responses. NF- $\mathrm{KB}$ performs its unique roles using two distinct signaling pathways, i.e., noncanonical and canonical pathways. The noncanonical pathway has a completely different signaling process, such as involving variable signaling molecules and leading to $\mathrm{p} 52 / \mathrm{RelB}$ dimer activation $[2,13]$. By contrast, in the canonical pathway, the

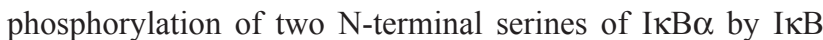
kinase (IKK) is followed by its ubiquitination and proteasomal degradation, finally leading to the nuclear translocation of dimerized $\mathrm{p} 50 / \mathrm{c}-\mathrm{Rel}$ and $\mathrm{p} 50 / \mathrm{RelA}$ of NF- $\mathrm{KB}$ complexes. After activation, the NF- $\mathrm{\kappa B} /$ RelA unit induces the transcription of several proinflammatory genes, displaying its prominent role through inflammation.

Although the purpose of this chapter is to review NFKB1 and $N F K B 1 A$ variants and their relation to specific inflammatory disorders, before proceeding, it is useful to mention the general relationship of $N F K B 1$ with some other diseases. In neurodegenerative diseases such as vascular cognitive impairment, NF- $\mathrm{KB}$ contribution may lead to demyelination, axonal loss, and memory impairment of astrocytes [14]. By contrast, in healing processes, elevated NF- $\mathrm{KB}$ activation through NFKB1 deletion enriches aggregation of both myofibroblasts and macrophages, leading to enhanced collagen deposition [15]. This finding is in agreement with Stone's findings in a mouse model of multiple sclerosis, which

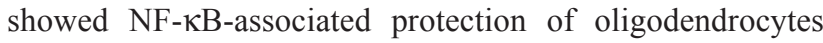
against inflammation [16].

\section{Atherosclerosis}

Being described as immune activation within the arterial wall in the presence of inflammatory mediators, atherosclerosis (AT) is believed to be a chronic immunoinflammatory disease. As NF- $\mathrm{KB}$ is accepted as regulating the expression of a wide range of genes cooperating with the distinct aspects of atherosclerotic pathogenesis [17], NFKB1 may be an appropriate candidate for investigating arterial wall inflammation-related disorders such as atherosclerosis and coronary artery disease (CAD) [18]. Özbilüm et al. [19] draw our attention to alveolar epithelial cells as a piece of evidence for the mechanism of the I $\mathrm{\kappa B} \alpha-\mathrm{NF}-\kappa \mathrm{B}-\mathrm{dependent}$ anti-inflammatory effect. Our results differed from those of Özbilüm et al.: we reported that rs 28362491 polymorphism has no association with AT; however, the AA genotype of the rs696 polymorphism of NFKB1A gene was considerably elevated in atherosclerotic patients in a Turkish population. Moreover, the combined genotype association of rs28362491 and rs696 polymorphisms with atherosclerosis was not statistically significant, suggesting that these two polymorphisms together play no role in the pathogenesis of atherosclerosis [20]. Although the findings represent NFKB1A rs696 polymorphism as a novel marker of susceptibility to atherosclerosis, the results from such analyses should be treated with caution because of the limited sample size.

NFKB1A $-826 \mathrm{C} / \mathrm{T}$ promoter polymorphism was reported as a risk factor for susceptibility to CAD, but NFKB1A $-297 \mathrm{C} / \mathrm{T}$ and $-881 \mathrm{~A} / \mathrm{G}$ polymorphisms had no associations, in a Turkish population [19], whereas Lai et al. [21] found that rs28362491 polymorphism had a critical role and was related to functional interleukin (IL)-6 expression in a Chinese Uygur population. In an Iranian subpopulation, $r s 28362491$ polymorphism, but not $N F K B 1 A-826 \mathrm{C} / \mathrm{T}$ polymorphism, was found to be significantly associated with the development and severity of CAD as an independent risk factor [22]. In research into an NFKB1 promoter variant in coronary heart diseases (CHDs) of people of European ancestry, Vogel et al. [23] reported that a variant previously found to lead to partial depletion of NF- $\mathrm{KB}$ p50 is associated with CHD. The participation of rs 28362491 polymorphism in CAD in Korean and Chinese populations was reported more recently [24, 25]. There is general agreement that inflammation occupies a pivotal role in both initiation and progression of coronary atherosclerosis is the necessarily condition for CHD. Jin et al. [25] concluded that the del/del genotype of rs28362491 is associated with the risk and the severity of the disease.

$\mathrm{NF}-\kappa \mathrm{B}$ is a good illustration of two sides of the same coin. While a majority of authors mention that NF- $\mathrm{KB}$ activation is associated with normal conditioning, Peterson et al. [26], using a murine model of Duchenne muscular dystrophy, report the importance of NF- $\mathrm{kB}$ blocking in normal cardiac function.

MicroRNAs (miRNAs) are noncoding, single-stranded RNAs around 20-22 nucleotides in length, which organize gene expression through posttranscriptional repression [27] and are members of a large array of remodification processes, such as cellular differentiation, proliferation, development, immunity, apoptosis, and angiogenesis [28-30], but these are linked to several chronic and acute diseases, such as heart diseases, cancer, acute organ injury, autoimmunity, and ischemic stroke, when they are dysregulated [31-34]. In a major advance for understanding inflammatory diseases, Taganov et al. [35] noted that an NF-kB-targeting actor, namely, mir146a, enhances the inflammatory response by being used as a feedback inhibitor of NF- $\mathrm{kB}$ activation. Generally, the expression level of mature miRNA-146a may be regulated by SNPs of pre-miR-146a. An SNP located in the stem region, namely, rs2910164, may modify the transcription of genes involved 
putatively in the pathogenesis of inflammation-related diseases, such as cardiovascular diseases, reducing the total amount of mature miRNA [36, 37].

More recently, literature has emerged that describes consistent findings for mir-146a SNP. Xiong et al. [38] reported that a G-to-C substitution in the precursor of mir-146a seems to lead to the enhanced expression of mature mir-146a. This is in agreement with findings by Guo et al. [39] that the function of TH-1 cells, which is necessary for the progression of acute coronary syndrome, is stimulated by increased mature mir-146a expression levels.

The following findings also seem to be consistent with this research, which found significant differences within atherosclerotic patients compared with control subjects, concerning pre-miR-146a rs2910164 polymorphism. The $G$ allele and GG genotype were associated with an elevated risk for atherosclerosis thus pre-miR-146a rs2910164 is assumed to play a role as a novel marker for possible atherosclerosis susceptibility [20].

\section{Morbid obesity}

The link between obesity and obesity-related disorders can be explained by inflammation, which is noticed as an elevation in circulating levels of C-reactive protein (CRP) with low-grade inflammation $[40,41]$. The debate about the association of $N F K B 1$ with obesity has gained fresh prominence, with many arguing that NF- $\mathrm{KB}$ is weakly initiated in a nonobese murine model of type 1 diabetes [42], whereas NF- $\kappa B$ is directly correlated with pancreatic $\beta$-cell failure within diabetes [43]. However, we previously concluded that the ins allele of $N F K B 1 \mathrm{rs} 28362491$ and/or ins/ins genotype is related to morbid obesity in a Turkish population [44]. These findings are in contrast to those of Stegger et al. [45], who found no substantial interaction between rs28362491 and gluteofemoral, abdominal, and general obesity in a Danish population.

Morbid obesity is correlated with elevated circulating systemic acute-phase proteins, namely, CRP, and the expression of CRP is regulated by the p50 homodimer of $N F K B 1$. We found that the rs28362491 deletion variant tends to decrease the p50 subunit level and that increased serum CRP levels are correlated with NFKB1 rs28362491 polymorphism [46]. By modulating serum levels of CRP, this polymorphism may be correlated with morbid obesity.

There is good evidence for an association among toll-like receptor (TLR) polymorphisms, hepatic fat accumulation, and chronic inflammation, and the NF- $\kappa \mathrm{B}$ gene appears to play a key role. We reported that TLR2 variants, such as rs5743708
$(\mathrm{G} / \mathrm{G})$, and high levels of liver enzymes, such as alanine transaminase, alkaline phosphatase, aspartate transaminase, and $\gamma$-glutamyl transpeptidase, are associated with high levels of CRP [44]. These results are important for 2 main reasons. First, detecting the ins allele of rs28362491 and Arg753Gln allele of rs5743708, combined with a high level of CRP, may offer better treatments in the future. Second, NFKB1 may be useful to monitor both the course and severity of liver disease, suggesting new trends of therapies for these conditions.

\section{Male infertility}

Male infertility accounts for approximately $50 \%$ of infertility cases, even though $60 \%$ of whole infertility cases are idiopathic [47]. Severe oligozoospermia or azoospermia is responsible for most idiopathic male infertility. The interaction between the egg and the sperm is a key point, but the molecular mechanisms of egg-sperm membrane protein binding and fusion reactions are not fully clarified.

$N F K B 1$ is a candidate gene in spermatogenesis, whose failure may lead to male infertility $[48,49]$. The relationship of the variants of the promoter sites of NFKB1 with numerous diseases has been studied widely. Ranganathan et al. [50] have associated decreased NFKB1 expression with poor sperm production.

The E-cadherin short interfering RNA (siRNA) is known to trigger the stimulation of $\mathrm{NF}-\mathrm{\kappa B}$ transcriptional activity [51]. $\alpha$-Catenin and E-cadherin are validated to be good indices of infertility [52]. Hernandez Gifford et al. [53] proposed anti-catenin/anti-cadherin antibodies for male contraception, and Purohit et al. [54] reported the absence of E-cadherin on the head domain of spermatozoa from oligospermic individuals; however, as yet, the precise mechanisms of both recognition and fusion processes remain to be elucidated. We found increased risk of development of male infertility associated with the presence of the ins allele of $N F K B 1$. Moreover, in the context of low E-cadherin expression, NFKB1 rs28362491 ins/ins and del/del genotypes are likely to display an essential role in the case of susceptibility to oligospermic male infertility [55]. In other works, we were not able to find any correlation of rs28362491 within NFKB1 or the rs696 polymorphisms within NFKB1A in cases of elevated apoptosis in oligospermia. However, we concluded that the rs28362491 heterozygosity is likely to play a protective role by altering oligospermia susceptibility [56]. Consistent with these findings, in the context of E-cadherin and fibronectin levels, we found that the insertion allele within the promoter region of NFKB1 is presumably a key function in the susceptibility to normospermic male infertility [57]. 
There is other evidence to suggest that the NF- $\mathrm{KB}$ also contributes to female infertility. In a murine model, Wang et al. confirmed the idea that intrauterine adhesion results in impaired pregnancy and concluded that NF- $\mathrm{KB}$ activation is notably increased within the endometrial tissues of patients with Asherman syndrome [58].

\section{Hashimoto disease}

Hashimoto disease is a common chronic inflammationbased disorder present in the thyroid gland influenced by the interplay between various cytokines, and the potential risk factors for Hashimoto disease have been studied widely for decades [59].

As NF- $\mathrm{KB}$ is at the center of all autoimmune diseases, and since inflammation is inevitable, we have previously analyzed the associations of polymorphisms of rs28362491 within NFKB1 and rs696 within NFKBIA with susceptibility to Hashimoto disease. There was no significant association between the frequency of the alleles of these two variants and the genotypes. In a combined genotype analysis of NFKBI and NFKBIA polymorphisms, instead, the ins/ins/AG combined genotype was negatively associated with Hashimoto disease, which predominantly depends on the $\mathrm{G}$ allele of rs 696 in the Turkish population. In the presence of at least one $\mathrm{G}$ allele, the IL-6 levels were also higher in patients with the del/ del genotype [60]. Elevated serum IL-6 levels were correlated with the del allele of rs2836249. Therefore, polymorphism of the functional $N F K B 1$ rs 28362491 promoter was significantly associated with modulated IL-6 levels in the population with Hashimoto disease [61].

\section{Graves disease}

Graves disease is classified as a distinctive organ-specific inflammatory and autoimmunity-based disease of the thyroid, defined by dermopathy, hyperthyroidism, an ocular disorder, and especially diffuse goiter. At least $79 \%$ of genetic factors are involved in this disorder; cooperation between several inflammation-related genes, such as NFKB1 and NFKBIA, and cytokines, may have an impact on the development of Graves disease. An association study within a Turkish population found that the rs $28362491 \mathrm{del} / \mathrm{ins}$ genotype is a possible candidate variation for the development of Graves disease, whereas the ins/ins genotype is likely to play a protective role in this disorder. By contrast, in the case of rs696, there were no statistical differences between the groups [62]. The levels of cytokines IL-1 $\beta$, IL-6, and tumor necrosis factor (TNF)- $\alpha$ showed remarkable associations with variations in NFKB1 rs28362491. Kurylowicz et al. [63] found that susceptibility to Graves disease is associated with NFKB1 rs28362491 polymorphism within a Polish population.

\section{Behçet syndrome}

Behçet syndrome is both a systemic autoimmune disorder and a chronic inflammatory disease defined by ocular inflammation, recurrent vasculitis, oral and genital ulcers, and skin lesions [64]. Although there is some evidence for the involvement of both environmental and genetic factors, Behçet syndrome remains classified as a disease of unknown origin. NFKB 1 and its inhibitor, NFKBIA, are important actors in the inflammatory cascade of Behçet syndrome.

The promoter region polymorphisms of NFKB1 in Behçet syndrome could lead to modified $N F K B 1$ expression, which then promotes altered inflammatory cytokine transcription and might clarify the elevated expression and serum concentrations of these cytokines. In an association study in a Turkish population, the association of NFKB1 rs28362491 polymorphism with the ins allele and ins/ins genotype of rs28362491 is found to increase susceptibility to Behçet syndrome by 1.8 - and 2.5fold, respectively [65] (Tables 1 and 2). There appears to be no doubt that NF- $\mathrm{KB}$ inhibition is caused by binding of an inhibitor (IKB $\alpha$ ) that is encoded by NFKBIA, and any instability of this binding may lead to progression of inflammatory diseases. Hung et al. [67], in their study of Behçet syndrome, found an association with NFKBIA promoter polymorphisms, including $-826 \mathrm{~T} / \mathrm{T},-826 \mathrm{C} / \mathrm{T}, 519 \mathrm{C} / \mathrm{T}$, and $-881 \mathrm{~A} / \mathrm{G}$, and $-550 \mathrm{~A} /$ $\mathrm{T}$, and reported a correlation with the $-826 \mathrm{~T} / \mathrm{T}$ genotype and characteristic skin lesions. Consistent with these studies, we observed an rs696 AA genotype within NFKBIA as a factor that leads to a 2.5-times-increased risk for development of Behçet syndrome [65]. By contrast, assuming them as variations, Kaustio et al. [68] associated NFKB1 mutations, such as I553M and H67R, with Behçet syndrome-like phenotypes.

\section{Glioma}

Elevated NF- $\mathrm{KB}$ activation has also been related to cancer progression [69]. In cancer, the process that controls gene expression in response to inflammatory stimuli combines its survival with both its phenotype and function with the rest of the tissue [70]. This is generally apparent in strictly compromised regulation of NF- $\kappa \mathrm{B}$ activity, which enables abnormal cohorts of the NF- $\kappa B$ target gene expression in cancer cells [71]. The conclusion is not only that the cells of surrounding 
Table 1. Genotype assessment of SNPs rs 28362491 within NFKB1A and rs696 within NFKB1 in inflammatory disorders and glioma in the Turkish population

\begin{tabular}{|c|c|c|c|c|c|c|c|}
\hline \multirow{2}{*}{ Study } & \multicolumn{3}{|c|}{ Controls, n (\%) } & \multicolumn{3}{|c|}{ Patients, n (\%) } & \multirow[t]{2}{*}{$P$} \\
\hline & ww & WD & DD & wW & WD & DD & \\
\hline \multicolumn{8}{|c|}{ Atherosclerosis [39] } \\
\hline rs28362491 & $46(32)$ & $74(51)$ & $25(17)$ & $49(33)$ & $65(43)$ & $36(24)$ & $>0.05$ \\
\hline rs696 & $20(14)$ & $82(56)$ & $43(30)$ & $33(22)$ & $65(43)$ & $52(35)$ & 0.02 \\
\hline \multicolumn{8}{|c|}{ Morbid obesity [46] } \\
\hline rs28362491 & $73(35)$ & $108(52)$ & $26(13)$ & $92(46.5)$ & $86(43.5)$ & $20(10)$ & 0.03 \\
\hline \multicolumn{8}{|c|}{ Male infertility [57] } \\
\hline rs28362491 & $45(30)$ & $83(55)$ & $22(15)$ & $59(39)$ & $63(42)$ & $28(19)$ & 0.03 \\
\hline rs696 & $25(16.7)$ & $84(56)$ & $41(27.3)$ & $24(16)$ & $94(63)$ & $32(21)$ & $>0.05$ \\
\hline \multicolumn{8}{|c|}{ Hashimoto disease [61] } \\
\hline rs28362491 & $50(27)$ & $113(69)$ & $27(14)$ & $26(22)$ & $76(63)$ & $18(16)$ & $>0.05$ \\
\hline rs696 & $26(14)$ & $130(68)$ & $34(18)$ & $23(19)$ & $74(62)$ & $23(19)$ & $>0.05$ \\
\hline \multicolumn{8}{|c|}{ Graves disease [62] } \\
\hline rs28362491 & $50(33.3)$ & $80(53.3)$ & $20(13.3)$ & $40(33.3)$ & $63(52.6)$ & $17(14.1)$ & $>0.05$ \\
\hline rs696 & $18(12)$ & $100(66.7)$ & $32(21.3)$ & $14(11.6)$ & $77(64.2)$ & $29(24.2)$ & $>0.05$ \\
\hline \multicolumn{8}{|c|}{ Behçet syndrome [65] } \\
\hline rs28362491 & $50(27)$ & $113(59)$ & $27(14)$ & $43(48)$ & $38(43)$ & $8(9)$ & 0.003 \\
\hline rs696 & $25(14)$ & $130(68)$ & $34(18)$ & $18(20)$ & $38(43)$ & $33(37)$ & 0.033 \\
\hline \multicolumn{8}{|l|}{ Glioma [66] } \\
\hline rs28362491 & $52(24)$ & $149(66.2)$ & $22(9.7)$ & $48(40)$ & $63(52.5)$ & $9(7.5)$ & 0.003 \\
\hline
\end{tabular}

SNP, single-nucleotide polymorphism; WW, wild homozygote (ins-ins for rs28362491, AA for rs696); WD, heterozygote (ins-del for rs28362491, AG for rs696); DD, mutant homozygote (del-del for rs28362491, GG for rs696).

tissue change their function and fail to support the organism exclusively, but also that the cancer cells function abnormally. Instability of NF- $\kappa \mathrm{B}$ and $\mathrm{I} \kappa \mathrm{B}$ interactions have been observed generally in several diseases; however, the mechanisms behind the association between certain variations within different genes and cancer development remain elusive.

Glioblastoma (glioblastoma multiforme), accounting for less than $2 \%$ of all human cancers, is the most malignant primary brain tumor in the adult nervous system [72, 73]. Although the origin of glioblastoma development is still unknown, some genetic modifications that lead to aberrant activity of pathways, such as proliferation, apoptosis, and cell cycle regulation, are considered to contribute to their pathogenesis $[74,75]$.

Deregulated NF- $\kappa \mathrm{B}$ activity has become a central issue in the development of most human cancers [76, 77]. NF- $\kappa B$ organizes cancer aggressiveness and development by increasing angiogenesis, antiapoptosis, and tumor proliferation and by reducing the immune response and thus managing pathogenetic regulation [78].

Numerous studies advocate the idea that several malignant tumor types, including glioblastomas, have strong connections with NF- $\kappa \mathrm{B}$ cascades $[5,79]$. We have evaluated 120 glioma samples and 225 controls. There are significant associations between insertion allele carriers and elevated risk of gliomas [66] (Tables 1 and 2). Previous studies reported conflicting results. Meta-analyses such as those conducted by Sun et al. [80] and Yu et al. [81], for instance, concluded that the deletion allele is both a risk and a protection against cancer susceptibility in populations with European or Asian ancestry. The rs28362491 del/del genotype appears related to bladder, prostate, oral, and ovarian cancers but not with hepatocellular carcinoma [82]. Concetti and Wilson reviewed the status of this polymorphism and concluded that rs28362491 polymorphism is disadvantageous for colorectal, gastric, liver, bladder, and thyroid cancers but advantageous for prostate, ovarian, and cervical cancers [83]. Similarly, rs28362491 polymorphism was found to be associated with decreased cancer risk [84], as well as the development of head and neck cancer [85], and rs696 polymorphism was found to be associated with colorectal cancer risk [86].

Various NFKB1 variations in specific pathways are associated with cancer progression, but blocking a signaling pathway in multifactorial diseases such as cancer may not be 
Table 2. Assessment of SNP alleles rs28362491 within NFKB1A and rs696 within NFKB1 in inflammatory disorders and glioma in the Turkish population

\begin{tabular}{|c|c|c|c|c|c|}
\hline Study & \multicolumn{2}{|c|}{$\begin{array}{c}\text { Controls } \\
\text { Allele, n (\%) }\end{array}$} & \multicolumn{2}{|c|}{$\begin{array}{c}\text { Patients } \\
\text { Allele, n (\%) }\end{array}$} & $P$ \\
\hline rs28362491 & ins, $166(57)$ & del, 124 (43) & ins, $163(54)$ & del, 137 (46) & $>0.05$ \\
\hline rs696 & A, $122(42)$ & G, 168 (58) & A, $131(44)$ & $\mathrm{G}, 169(56)$ & $>0.05$ \\
\hline \multicolumn{6}{|c|}{ Morbid obesity [46] } \\
\hline rs28362491 & ins, $254(61)$ & del, 160 (39) & ins, $270(68)$ & del, 126 (32) & $<0.05$ \\
\hline \multicolumn{6}{|c|}{ Male infertility [57] } \\
\hline rs28362491 & ins, $173(58)$ & del, 127 (42) & ins, $181(60)$ & del, $119(40)$ & $>0.05$ \\
\hline rs696 & A, $142(47)$ & G, $158(53)$ & A, $134(44.7)$ & G, $166(55.3)$ & $>0.05$ \\
\hline \multicolumn{6}{|c|}{ Hashimoto disease [61] } \\
\hline rs28362491 & ins, $213(56)$ & del, 167 (44) & ins, $128(53)$ & del, 112 (47) & $>0.05$ \\
\hline rs696 & $A, 180(48)$ & $\mathrm{G}, 198(52)$ & $A, 120(50)$ & $\mathrm{G}, 120(50)$ & $>0.05$ \\
\hline \multicolumn{6}{|c|}{ Graves disease [62] } \\
\hline rs28362491 & ins, $180(60)$ & del, 120 (40) & ins, $143(59.6)$ & del, 97 (40.4) & $>0.05$ \\
\hline rs696 & A, $136(45.3)$ & $\mathrm{G}, 164(54.7)$ & A, 105 (43.8) & G135 (56.3) & $>0.05$ \\
\hline \multicolumn{6}{|c|}{ Behçet syndrome [65] } \\
\hline rs28362491 & ins, $213(56)$ & del, 167 (44) & ins, $124(70)$ & del, 54 (30) & 0.004 \\
\hline rs696 & A, $180(48)$ & G, $198(52)$ & $A, 72(42)$ & $\mathrm{G}, 104(58)$ & $>0.05$ \\
\hline \multicolumn{6}{|l|}{ Glioma [66] } \\
\hline rs28362491 & ins, $257(57.1)$ & del, 193 (42.9) & ins, $159(66.3)$ & del, 81 (33.7) & 0.01 \\
\hline rs696 & A, $180(48)$ & G, 198 (52) & $A, 72(42)$ & G, 104 (58) & $>0.05$ \\
\hline
\end{tabular}

SNP, single-nucleotide polymorphism.

appropriate because the polymorphisms can be advantageous for the individual.

\section{NF- $K B$ as a therapeutic target for inflammatory diseases and cancer}

Abnormal activation of NF- $\mathrm{\kappa B}$ is commonly noticed in several inflammatory diseases and cancers. Thus, to advance therapeutic applications in cancer and inflammatory diseases, there has been increased interest in inhibiting NF- $\kappa B$ signaling. Many natural products used for their alleged anti-inflammatory and cancer-preventing activities have been found to inhibit NF- $\mathrm{KB}$; therefore, dysregulations in NF- $\mathrm{KB}$ signaling may potentially be connected to certain cancers and inflammatory diseases [87, 88]. Characterization of these natural products is warranted.

In lymphoid, colon, breast, skin, and prostate cancers, prior persistent activation of $\mathrm{NF}-\mathrm{\kappa B}$ signaling is found; hence, the therapeutic inhibition of $\mathrm{NF}-\kappa \mathrm{B}$ signaling in malignant cells may provide a strategy for anticancer drug development.
Miller et al. screened approximately 2,800 clinically approved drugs to identify small molecule inhibitors of NF- $\kappa B$ signaling. Drugs such as bithionol, emetine, tribromsalan, metformin, lestaurtinib, sunitinib malate, and narasin were observed to inhibit NF- $\kappa \mathrm{B}$ signaling through inhibition of $\mathrm{I} \kappa \mathrm{B} \alpha$ phosphorylation, whereas bortezomib, chromomycin A3, and ecteinascidin 743 act through other mechanisms [89]. According to these findings, many currently approved pharmaceuticals have unpredictable impacts on the NF- $\mathrm{KB}$ signaling cascade; therefore, more detailed characterization of approved drugs might broaden the horizon of knowledge of their molecular mechanisms. Yamamoto et al. [90] highlighted a type of drug utilized in the treatment of inflammatory disease, which has an impact on NF- $\mathrm{KB}$ activity, which, in turn, leads to numerous therapeutic strategies aimed at blocking NF- $\kappa \mathrm{B}$ activity.

According to a survey conducted by Tak and Firestein [91], the mode of action of corticosteroids, preferred in the treatment of psoriasis, asthma, rheumatoid arthritis, and inflammatory bowel disease, for instance, is presuma-

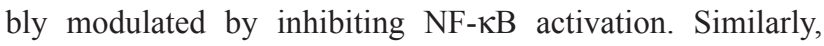


nonsteroidal anti-inflammatory drugs, such as leflunomide and sulfasalazine, inhibit nuclear translocation of NF- $\kappa B$ by

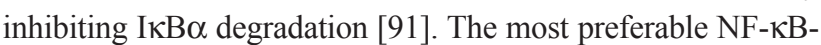
related inhibitors are selective I $\kappa \mathrm{B}$ kinase inhibitors that block

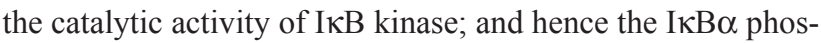
phorylation; proteasome inhibitors; inhibitors that prevent nuclear translocation of NF- $\mathrm{KB}$ subunits; and drugs that block the DNA-binding activity of NF- $\kappa$ B. Kiliccioglu et al. [92], e.g., reported the importance of NF- $\mathrm{KB}$ and Hsp-27 inhibition, along with therapies for inhibition of androgen receptor variant-7. However, because of the lack of specificity of these drugs, relatively high concentrations were required to achieve strong inhibition of NF- $\kappa \mathrm{B}$.

We concluded in an in vitro study that metformin serves as a potential agent for breast cancer treatment in a dosedependent manner. We observed that metformin blocked $\mathrm{NF}-\kappa \mathrm{B}$ through the prevention of the latter's nuclear translocation and reduced the expression of proteins such as matrix metalloproteinase (MMP)-2 and MMP-9, which are required for the invasion in breast cancer [93]. Metformin might have a protective function against breast cancer by regulating NF- $\mathrm{NB}$.

\section{Conclusion}

There are differences between mechanisms of regulating NFKB1 and NFKB1A and the autoimmune diseases discussed. We sought to supply a general update on the association of NFKB1 and NFKB1A variations with their inhibitory effects on inflammatory diseases, as blocking NF- $\kappa B$ activation may open a path to new therapies. Despite its exploratory nature, the analysis of these polymorphisms undertaken here offers some insight into new therapies for, and has extended our knowledge of, the genetic variation in inflammation-related disorders.

Author contributions. GK-S and GY made substantial contributions to the conception and design of this review. TS contributed substantially to review of the literature, and all authors contributed to its analysis and interpretation. All authors contributed to drafting of the manuscript, and GY and TS critically revised it. All authors approved the final version submitted for publication and take responsibility for statements made in the published article.

Conflict of interest statement. The authors have each completed and submitted an International Committee of Medical Journal Editors Uniform Disclosure Form for Potential Conflicts of Interests. None of the authors has any potential or actual conflict of interest to disclose in relation to the published article.

Data sharing statement. No data sets were generated or analyzed during the present study. The present review was based on the references cited.

\section{References}

[1] Coussens LM, Werb Z. Inflammation and cancer. Nature. 2002; 420:860-7.

[2] Oeckinghaus A, Ghosh S. The NF- $\kappa B$ family of transcription factors and its regulation. Cold Spring Harb Perspect Biol. 2009; 1:a000034. doi: 10.1101/cshperspect.a000034

[3] Héron E, Deloukas P, van Loon APGM. The complete exon-intron structure of the 156-kb human gene $N F K B 1$, which encodes the p105 and p50 proteins of transcription factors NF- $\kappa$ B and I $\kappa B-\gamma$ : implications for NF- $\kappa \mathrm{B}-$ mediated signal transduction. Genomics. 1995; 30:493-505.

[4] Le Beau MM, Ito C, Cogswell P, Espinosa R 3rd, Fernald AA, Baldwin AS Jr. Chromosomal localization of the genes encoding the

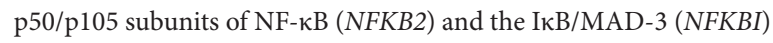
inhibitor of NF- $\kappa B$ to $4 \mathrm{q} 24$ and $14 \mathrm{q} 13$, respectively. Genomics. 1992; 14:529-31.

[5] Karban AS, Okazaki T, Panhuysen CI, Gallegos T, Potter JJ, BaileyWilson JE, et al. Functional annotation of a novel NFKB1 promoter polymorphism that increases risk for ulcerative colitis. Hum Mol Genet. 2004; 13:35-45.

[6] Zhou Y, Eppenberger-Castori S, Marx C, Yau C, Scott GK, Eppenberger U, Benz CC. Activation of nuclear factor- $\kappa \mathrm{B}(\mathrm{NF} \kappa \mathrm{B})$ identifies a high-risk subset of hormone-dependent breast cancers. Int J Biochem Cell Biol. 2005; 37:1130-44.

[7] Li R-N, Hung Y-H, Lin C-H, Chen Y-H, Yen J-H. Inhibitor IкBa promoter functional polymorphisms in patients with rheumatoid arthritis. J Clin Immunol. 2010; 30:676-80.

[8] Chen F, Castranova V, Shi X, Demers LM. New insights into the role of nuclear factor- $\kappa \mathrm{B}$, a ubiquitous transcription factor in the initiation of diseases. Clin Chem. 1999; 45:7-17.

[9] Dong QG, Sclabas GM, Fujioka S, Schmidt C, Peng B, Wu T, et al. The function of multiple I $\kappa \mathrm{B}$ : NF- $\kappa \mathrm{B}$ complexes in the resistance of cancer cells to Taxol-induced apoptosis. Oncogene. 2002; 21:6510-19.

[10] Hayden MS, Ghosh S. Shared principles in NF- $\kappa B$ signaling. Cell. 2008; 132:344-62.

[11] Karin M. NF- $\mathrm{kB}$ as a critical link between inflammation and cancer. Cold Spring Harb Perspect Biol. 2009; 1:a000141. doi: 10.1101/ cshperspect.a000141

[12] Madrid LV, Mayo MW, Reuther JY, Baldwin AS Jr. Akt stimulates the transactivation potential of the RelA/p65 Subunit of NF- $\kappa B$ through utilization of the $\mathrm{I} \kappa \mathrm{B}$ kinase and activation of the mitogenactivated protein kinase p38. J Biol Chem. 2001; 276:18934-40.

[13] Gupta SC, Sundaram C, Reuter S, Aggarwal BB. Inhibiting NF- $\kappa B$ activation by small molecules as a therapeutic strategy. Biochim Biophys Acta. 2010; 1799:775-87.

[14] Saggu R, Schumacher T, Gerich F, Rakers C, Tai K, Delekate A, Petzold GC. Astroglial NF-kB contributes to white matter damage 
and cognitive impairment in a mouse model of vascular dementia. Acta Neuropathol Commun. 2016; 4:76. doi: 10.1186/s40478-0160350-3

[15] Best KT, Lee FK, Knapp E, Awad HA, Loiselle AE. Deletion of NFKB1 enhances canonical NF- $\kappa$ B signaling and increases macrophage and myofibroblast content during tendon healing. Sci Rep. 2019; 9:10926. doi: 10.1038/s41598-019-47461-5

[16] Stone S, Jamison S, Yue Y, Durose W, Schmidt-Ullrich R, Lin W. NF- $\mathrm{kB}$ activation protects oligodendrocytes against inflammation. J Neurosci. 2017; 20;37:9332-44.

[17] Gareus R, Kotsaki E, Xanthoulea S, van der Made I, Gijbels MJ, Kardakaris R, et al. Endothelial cell-specific NF- $\kappa B$ inhibition protects mice from atherosclerosis. Cell Metab. 2008; 8:372-83.

[18] Fontaine-Bisson B, Wolever TM, Connelly PW, Corey PN, El-Sohemy A. NF-kB-94Ins/Del ATTG polymorphism modifies the association between dietary polyunsaturated fatty acids and HDL-cholesterol in two distinct populations. Atherosclerosis. 2009; 204:465-70.

[19] Özbilüm N, Arslan S, Berkan Ö, Yanartaş M, Aydemir EI. The role of NF- $\kappa B 1 A$ promoter polymorphisms on coronary artery disease risk. Basic Clin Pharmacol Toxicol. 2013; 113:187-92.

[20] Oner T, Arslan C, Yenmis G, Arapi B, Tel C, Aydemir B, Sultuybek GK. Association of NFKB1A and microRNAs variations and the susceptibility to atherosclerosis. J Genet. 2017; 96:251-9.

[21] Lai H-M, Li X-M, Yang Y-N, Ma Y-T, Xu R, Pan S, et al. Genetic variation in NFKB1 and NFKBIA and susceptibility to coronary artery disease in a Chinese Uygur population. PLoS One. 2015; 10:e0129144. doi: 10.1371/journal.pone.0129144

[22] Seidi A, Mirzaahmadi S, Mahmoodi K, Soleiman-Soltanpour M. The association between NFKB1 -94ATTG ins/del and NFKB1A $826 \mathrm{C} / \mathrm{T}$ genetic variations and coronary artery disease risk. Mol Biol Res Commun. 2018; 7:17-24.

[23] Vogel U, Jensen MK, Due KM, Rimm EB, Wallin H, Nielsen MR, et al. The NFKB1 ATTG ins/del polymorphism and risk of coronary heart disease in three independent populations. Atherosclerosis. 2011; 219:200-4.

[24] Kim SK, Jang HM, Kim D-Y. The promoter polymorphism of NFKB1 gene contributes to susceptibility of ischemic stroke in Korean population. J Exerc Rehabil. 2018;14:1096-1100.

[25] Jin S-Y, Luo J-Y, Li X-M, Liu F, Ma Y-T, Gao X-M, Yang Y-N. NFKB1 gene rs28362491 polymorphism is associated with the susceptibility of acute coronary syndrome. Biosci Rep. 2019; 39:BSR20182292. doi: 10.1042/BSR20182292

[26] Peterson JM, Wang DJ, Shettigar V, Roof SR, Canan BD, Bakkar N, et al. NF- $\mathrm{kB}$ inhibition rescues cardiac function by remodeling calcium genes in a Duchenne muscular dystrophy model. Nat Commun. 2018; 9:3431. doi: 10.1038/s41467-018-05910-1.

[27] Bartel DP. MicroRNAs: genomics, biogenesis, mechanism, and function. Cell. 2004; 116:281-97.

[28] Chen Y, Fu LL, Wen X, Liu B, Huang J, Wang JH, et al. Oncogenic and tumor suppressive roles of microRNAs in apoptosis and autophagy. Apoptosis. 2014; 19:1177-89.

[29] O'Neill LA, Sheedy FJ, McCoy CE. MicroRNAs: the fine-tuners of Toll-like receptor signalling. Nat Rev Immunol. 2011; 11: 163-75.

[30] Winter J, Jukng S, Keller S, Gregory RI, Diederich S. Many roads to maturity: microRNA biogenesis pathways and their regulation. Nat Cell Biol. 2009; 11:228-34.

[31] Ma Y, Wang J, Wang Y, Yang G-Y. The biphasic function of microglia in ischemic stroke. Prog Neurobiol. 2017; 157:247-72.
[32] Bhalala OG, Srikanth M, Kessler JA. The emerging roles of microRNAs in CNS injuries. Nat Rev Neurol. 2013; 9:328-39.

[33] Zhang L, Huang J, Yang N, Greshock J, Megraw MS, Giannakakis A, et al. MicroRNAs exhibit high frequency genomic alterations in human cancer. Proc Natl Acad Sci USA. 2006; 103:9136-41.

[34] Davidson-Moncada J, Papavasiliou FN, Tam W. MicroRNAs of the immune system. Roles in inflammation and cancer. Ann N Y Acad Sci. 2010; 1183:183-94.

[35] Taganov KD, Boldin MP, Chang K-J, Baltimore D.

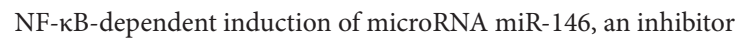
targeted to signaling proteins of innate immune responses. Proc Natl Acad Sci USA. 2006; 103:12481-86.

[36] Hashemi M, Eskandari-Nasab E, Zakeri Z, Atabaki M, Bahari G, et al. Association of premiRNA-146a rs2910164 and pre-miRNA-499 rs3746444 polymorphisms and susceptibility to rheumatoid arthritis. Mol Med Rep. 2013; 7:287-91.

[37] Jazdzewski K, Murray EL, Franssila K, Jarzab B, Schoenberg DR, de la Chapelle A. Common SNP in premiR-146a decreases mature $\mathrm{miR}$ expression and predisposes to papillary thyroid carcinoma. Proc Natl Acad Sci USA. 2008; 105:7269-74.

[38] Xiong XD, Cho M, Cai XP, Cheng J, Jing X, Cen JM, et al. A common variant in pre-miR-146 is associated with coronary artery disease risk and its mature miRNA expression. Mutat Res Fund Mol. 2014; 761:15-20.

[39] Guo M, Mao X, Ji Q, Lang M, Li S, Peng Y, et al. miR146a in PBMCs modulates Th1 function in patients with acute coronary syndrome. Immunol Cell Biol. 2010; 88:555-64.

[40] Dalmas E, Rouault C, Abdennour M, Rovere C, Rizkalla S, Bar-Hen A, et al. Variations in circulating inflammatory factors are related to changes in calorie and carbohydrate intakes early in the course of surgery-induced weight reduction. Am J Clin Nutr. 2011; 94:450-8.

[41] Paepegaey AC, Genser L, Bouillot J-L, Oppert J-M, Clément K, Poitou C. High levels of CRP in morbid obesity: the central role of adipose tissue and lessons for clinical practice before and after bariatric surgery. Surg Obes Relat Dis. 2015; 11:148-54.

[42] Irvin AE, Jhala G, Zhao Y, Blackwell TS, Krishnamurthy B, Thomas HE, Kay TWH. NF- $\kappa$ B is weakly activated in the NOD mouse model of type 1 diabetes. Sci Rep. 2018; 8:4217. doi: 10.1038/ s41598-018-22738-3

[43] Meyerovich K, Ortis F, Cardozo AK. The non-canonical NF-кB pathway and its contribution to $\beta$-cell failure in diabetes. J Mol Endocrinol. 2018; 61:F1-6.

[44] Yenmis G, Soydas T, Arkan H, Tasan E, Kanigur Sultuybek G. Genetic variation in NFKB1 gene influences liver enzyme levels in morbidly obese women. Arch Iran Med. 2018; 21:13-18.

[45] Stegger JG, Schmidt EB, Berentzen TL, Tjønneland A, Vogel U, Rimm E, et al. Interaction between obesity and the NFKB1 - 94ins/ delATTG promoter polymorphism in relation to incident acute coronary syndrome: a follow up study in three independent cohorts. PLoS One. 2013; 8:1-8.

[46] Soydas T, Karaman O, Arkan H, Yenmis G, Ilhan MM, Tombulturk K, et al. The correlation of increased CRP levels with NFKB1 and TLR2 polymorphisms in the case of morbid obesity. Scand J Immunol. 2016; 84:278-3.

[47] Guzick DS, Overstreet JW, Factor-Litvak P, Brazil CK, Nakajima ST, Coutifaris C, et al. Sperm morphology, motility, and concentration in fertile and infertile men. N Engl J Med. 2001; 345:1388-93.

[48] Carlsen H, Alexander G, Austenaa LMI, Ebihara K, Blomhoff R. Molecular imaging of the transcription factor NF-kB, a primary regulator of stress response. Mutat Res. 2004; 551:199-211. 
[49] Yamamoto Y, Gaynor RB. IкB kinases: key regulators of the NF-кB pathway. Trends Biochem Sci 2004; 29:72-9.

[50] Ranganathan P, Kattal N, Moustafa MH, Sharma RK, Thomas AJ Jr, Agarwal A. Correlation of nuclear factor kappa B (NFKB) with sperm quality and clinical diagnoses in infertile men. Fertil Steril. 2002; 78:S95 [abstract]

[51] Solanas G, Porta-de-la-Riva M, Agustí C, Casagolda D, SánchezAguilera F, Larriba MJ, et al. E-Cadherin controls $\beta$-catenin and NF- $\mathrm{kB}$ transcriptional activity in mesenchymal gene expression. J Cell Sci. 2008; 121:2224-34.

[52] Aberle H, Schwartz H, Kemler R. Cadherin-catenin complex: protein interactions and their implications for cadherin function. J Cell Biochem. 1996; 61:514-23.

[53] Hernandez Gifford JA, Hunzicker-Dunn ME, Nilson JH. Conditional deletion of beta-catenin mediated by Amhr2cre in mice causes female infertility. Biol Reprod. 2009; 80:1282-92.

[54] Purohit S, Brahmaraju M, Palta A, Shukla S, Laloraya M, Kumar PG. Impaired E-Cadherin expression in human spermatozoa in a male factor infertility subset signifies e-cadherin-mediated adhesion mechanisms operative in sperm-oolemma interactions. Biochem Biophys Res Commun. 2004; 316:903-9.

[55] Tunçdemir M, Yenmiş G, Tombultürk K, Arkan H, Soydaş T, Tek RB, et al. NFKB1 rs28362491 and pre-miRNA-146a rs2910164 SNPs on E-Cadherin expression in case of idiopathic oligospermia: a case-control study. Int J Reprod BioMed (Yazd). 2018; 16:247-54.

[56] Tek B, Elçin P, Tunçdemir M, Onaran İ, Özkara H, Kanıgür Sultuybek G. A role for heterozygosity of NF- $\kappa B 1$ rs 28362491 polymorphism in patients with idiopathic oligospermia. Arch Iran Med. 2016; 19:275-81.

[57] Elcin P, Burak Tek R, Koc A, Arkan H, Ozkara H, KanigurSultuybek G. Effects of SNPs in nuclear factor kappa-B1, poly (ADP-ribose) polymerase-1 genes on E-Cadherin and fibronectin levels in case of male infertility. Androl Gynecol Curr Res. 2015; $3: 1-7$.

[58] Wang X, Ma N, Sun Q, Huang C, Liu Y, Luo X. Elevated NF-кB signaling in Asherman syndrome patients and animal models. Oncotarget. 2017; 8:15399-406.

[59] Chistiakov DA. Immunogenetics of Hashimoto's thyroiditis. J Autoimmune Dis. 2005; 2:1. doi: 10.1186/1740-2557-2-1

[60] Koc A, Aydin Sayitoglu M, Karakurt F, Batar B, Niyazoglu M, Celik O, et al. Association of three SNPs in the PARP-1 gene with Hashimoto's thyroiditis. Hum Genome Var. 2014; 1:14016. doi: 10.1038/hgv.2014.16

[61] Koc A, Batar B, Celik O, Onaran I, Tasan E, Sultuybek GK. Polymorphism of the NFKB1 affects the serum inflammatory levels of IL-6 in Hashimoto thyroiditis in a Turkish population. Immunobiology. 2014; 219:531-6.

[62] Niyazoglu M, Baykara O, Koc A, Aydoğdu P, Onaran I, Dellal FD,

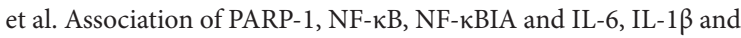
TNF- $\alpha$ with Graves disease and Graves ophthalmopathy. Gene. 2014; 547:226-32.

[63] Kurylowicz A, Miśkiewicz P, Bar-Andziak E, Nauman J, Bednarczuk $\mathrm{T}$. Association of polymorphism in genes encoding $\mathrm{\kappa} B$ inhibitors (IкB) with susceptibility to and phenotype of Graves' disease: a case-control study. Thyroid Res. 2009; 2:10. doi: 10.1186/17566614-2-10

[64] Kaya Tİ. Genetics of Behçet's disease. Patholog Res Int. 2012; 2012:912589. doi: 10.1155/2012/912589
[65] Yenmis G, Oner T, Cam C, Koc A, Kucuk OS, Yakicier MC, et al. Association of NFKB1 and NFKBIA polymorphisms in relation to susceptibility of Behçet's disease. Scand J Immunol. 2014; 81:81-6.

[66] Kına I, Kanigur Sultuybek G, Soydas T, Yenmis G, Biceroglu H, Dirican A, et al. Variations in Toll-like receptor and nuclear factor-kappa B genes and the risk of glioma. Br J Neurosurg. 2019; 33:165-70.

[67] Hung Y-H, Wu C-C, Ou T-T, Lin C-H, Li R-N, Lin Y-C, et al. IкBa promoter polymorphisms in patients with Behçet's disease. Dis Markers. 2010; 28:55-62.

[68] Kaustio M, Haapaniemi E, Göös H, Hautala T, Park G, Syrjänen J, et al. Damaging heterozygous mutations in NFKB1 lead to diverse immunologic phenotypes. J Allergy Clin Immunol. 2017; 140:782-96.

[69] Terzić J, Grivennikov S, Karin E, Karin M. Inflammation and colon cancer. Gastroenterology. 2010; 138:2101-14.e5.

[70] Vlahopoulos SA, Cen O, Hengen N, Agan J, Moschovi M, Critselis E, et al. Dynamic aberrant NF- $\mathrm{BB}$ spurs tumorigenesis: a new model encompassing the microenvironment. Cytokine Growth Factor Rev. $2015 ; 26: 389-403$.

[71] Grivennikov S, Karin M. Dangerous liaisons: STAT3 and NF- $\kappa B$ collaboration and crosstalk in cancer. Cytokine Growth Factor Rev. 2010; 21:11-19.

[72] Reardon DA, Wen PY. Therapeutic advances in the treatment of glioblastoma: rationale and potential role of targeted agents. Oncologist. 2006; 11:152-64.

[73] Maes W, Van Gool SW. Experimental immuno-therapy for malignant glioma: lessons from two decades of research in the GL261 model. Cancer Immunol Immunother. 2011; 60:153-60.

[74] Furnari FB, Fenton T, Bachoo RM, Mukasa A, Stommel JM, Stegh A, et al. Malignant astrocytic glioma: genetics, biology, and paths to treatment. Genes Dev. 2007; 21:2683-710.

[75] Cancer Genome Atlas Research Network. Comprehensive genomic characterization defines human glioblastoma genes and core pathways. Nature 2008; 455:1061-8.

[76] Szajnik M, Szczepanski MJ, Czystowska M, Elishaev E, Mandapathil M, Nowak-Markwitz E, et al. TLR4 signaling induced by lipopolysaccharide or paclitaxel regulates tumour survival and chemoresistance in ovarian cancer. Oncogene 2009; 28:4353-63.

[77] Kim S, Karin M. Role of TLR2-dependent inflammation in metastatic progression. Ann N Y Acad Sci. 2011; 1217:191-206.

[78] Wang H, Cho CH. Effect of NF- $\mathrm{kB}$ signaling on apoptosis in chronic inflammation-associated carcinogenesis. Curr Cancer Drug Targets. 2010; 10:593-9.

[79] Hegazy DM, O'Reilly DA, Yang BM, Hodgkinson AD, Millward BA, Demaine AG. NFkB polymorphisms and susceptibility to type 1 diabetes. Genes Immun. 2001; 2:304-8.

[80] Sun XF, Zhang H. NFKB and NFKBI polymorphisms in relation to susceptibility of tumour and other diseases. Histol Histopathol. 2007; 22:1387-98.

[81] Yu Y, Wan Y, Huang C. The biological functions of NF-kB1 (p50) and its potential as an anti-cancer target. Curr Cancer Drug Targ. 2009; 9:566-71.

[82] Yang X, Li P, Tao J, Qin C, Cao Q, Gu J, et al. Association between NFKB1 -94ins/del ATTG promoter polymorphism and cancer susceptibility: an updated meta-analysis. Int J Genomics. 2014; 2014:612972. doi: 10.1155/2014/612972

[83] Concetti J, Wilson CL. NFKB1 and cancer: friend or foe? Cells. 2018; 7:133. doi: $10.3390 /$ cells7090133 
[84] Fu W, Zhuo Z-J, Chen Y-C, Zhu J, Zhao Z, Jia W, et al. NFKB1 -94insertion/deletion ATTG polymorphism and cancer risk: evidence from 50 case-control studies. Oncotarget. 2017; 8: 9806-22.

[85] Li L, Zhang ZT. Genetic association between NFKBIA and NFKB1 gene polymorphisms and the susceptibility to head and neck cancer: a meta-analysis. Dis Markers. 2019; 2019:6523837. doi: $10.1155 / 2019 / 6523837$

[86] Simonian M, Mosallayi M, Miraghajani M, Feizi A, Khosravi S, Salehi AR, et al. Single nucleotide polymorphism rs696 in miR449a binding site of NFKBIA gene is correlated with risk of colorectal cancer. Gastroenterol Hepatol Bed Bench. 2018; 11:48-53.

[87] Westbrook AM, Szakmary A, Schiestl RH. Mechanisms of intestinal inflammation and development of associated cancers: lessons learned from mouse models. Mutat. Res. 2010; 705:40-59.

[88] Kanigur Sultuybek G, Soydas T, Yenmis G. NF- $\mathrm{kB}$ as the mediator of metformin's effect on ageing and ageing-related diseases. Clin Exp Pharmacol Physiol. 2019; 46:413-22.
[89] Miller SC, Huang R, Sakamuru S, Shukla SJ, Attene-Ramos MS, Shinn $\mathrm{P}$, et al. Identification of known drugs that act as inhibitors of NF- $\kappa B$ signaling and their mechanism of action. Biochem Pharmacol. 2010; 79:1272-80.

[90] Yamamoto M, Horie R, Takeiri M, Kozawa I, Umezawa K. Inactivation of NF- $\kappa \mathrm{B}$ components by covalent binding of (-)-dehydroxymethylepoxyquinomicin to specific cysteine residues. J Med Chem. 2008; 51:5780-8.

[91] Tak PP, Firestein GS. NF-кB: a key role in inflammatory diseases. J Clin Invest. 2001; 107:7-11.

[92] Kiliccioglu I, Konac E, Dikmen AU, Sozen S, Bilen CY. Hsp-27 and $\mathrm{NF-KB}$ pathway is associated with AR/AR-V7 expression in prostate cancer cells. Gene. 2019; 697:138-43.

[93] Yenmis G. Investigation of the molecular mechanisms of the effect of metformin on aging and cancer [PhD dissertation]. Istanbul, Turkey: University of Istanbul; 2019. Thesis No. 541930. [in Turkish, English abstract]. Available from: https://tez.yok.gov.tr/UlusalTezMerkezi/tezSorguSonucYeni.jsp 